Article

\title{
Empirical Coastal Atmospheric Corrosion of Masonry Metal Wall Ties
}

\author{
Igor A. Chaves ${ }^{1, * \mathbb{D}}$, Sean de Prazer ${ }^{2} \mathbb{D}$, Barbara Jardim do Nascimento ${ }^{1}$ and Gregory Flowers ${ }^{2}$ \\ 1 Centre for Infrastructure Performance and Reliability, The University of Newcastle, \\ Newcastle, NSW 2308, Australia; Barbara.JardimDoNascimento@uon.edu.au \\ 2 Department of Mines, Industry Regulation and Safety, Government of Western Australia, \\ Perth, WA 6107, Australia; sean.deprazer@dmirs.wa.gov.au (S.d.P.); greg.flowers@dmirs.wa.gov.au (G.F.) \\ * Correspondence: igor.chaves@newcastle.edu.au; Tel.: +61-(02)-4921-2006
}

Citation: Chaves, I.A.; de Prazer, S.; Jardim do Nascimento, B.; Flowers, G Empirical Coastal Atmospheric Corrosion of Masonry Metal Wall Ties. Corros. Mater. Degrad. 2021, 2, 657-665. https://doi.org/10.3390/ cmd2040035

Academic Editor: María Criado Sanz

Received: 10 September 2021

Accepted: 8 November 2021

Published: 11 November 2021

Publisher's Note: MDPI stays neutral with regard to jurisdictional claims in published maps and institutional affiliations.

Copyright: (c) 2021 by the authors. Licensee MDPI, Basel, Switzerland. This article is an open access article distributed under the terms and conditions of the Creative Commons Attribution (CC BY) license (https:// creativecommons.org/licenses/by/ $4.0 /)$.

\begin{abstract}
Not counting domestic dwellings, it has been estimated that in Australia alone, some tens of thousands of masonry buildings and structures have exceeded their design life, with many of these being at risk of partial (or worse) collapse from falling or dislodged masonry. This has significant implications for human life but also for the urban environment and economic health of building owners, managers, and insurers and for local and national economies. This risk can mainly be attributed to the slow deterioration of masonry under atmospheric and other environments and the corrosion of so-called wall ties. Wall ties are relatively thin pieces of steel that tie the outer leaf of masonry walls to the stabilized inner leaf. The problem is likely severe for scenarios such as cyclonic and earthquake events, as they cause area-wide damage and the potential wide-spread loss of human life-losses that could be prevented by timely intervention. This paper reports on the in situ inspection of two case study buildings and the data obtained from controlled wall tie corrosion field trials, which are used to develop predictive models of structural response. These models will inform practical tools that will be developed for building assessment, cost-effective monitoring, and rectification, assisting in the management of existing masonry buildings.
\end{abstract}

Keywords: masonry; double leaf; veneer walls; atmospheric; corrosion; structural stability

\section{Introduction}

The corrosion of wall ties, small and numerous metal fitments that provide structural stability for masonry brick veneer and double brick cavity walls, is often not observed until it is too late. This is particularly relevant to Western Australia (WA), where a significant proportion of existing and new infrastructure is predominantly built with double-brick cavity wall construction [1]. As the corrosion of wall ties is often the most severe at the interface of or within the brick mortar bed joint, visual examination through borescopes may over-estimate the integrity of a tie when the visible part of the tie within the cavity can often have only minor corrosion. The difficulty of inspecting walls in order to ascertain the level of corrosion and thus the strength loss that the wall fitments might have suffered is often related to access requirements, disruption to building use, or adverse visible changes in the building fabric. Moreover, despite modern corrosion-resistant wall tie materials becoming available and standardized (e.g., stainless steel), a certain level of risk remains across building stocks. There is particular concern with buildings of heritage value, where both the condition of wall ties and destructive inspection techniques are unsuitable. This highlights a need for other approaches to ensure the integrity of ageing masonry walls.

A relatively inexpensive remediation solution exists in the form of self-tapping Helifix ${ }^{\circledR}$ wall ties (Mount Druitt, Sydney, NSW 2770, Australia), which are drilled directly into the outer leaf through the load bearing inner wall leaf to provide further stability. The difficulty, however, lies in determining which walls are at risk in order to intervene before collapse. With a significant proportion of masonry veneer and cavity wall constructions 
being erected prior to modern material selection standards, many are at end, or even past, design service life and are at significant risk of wall failure/falling brickwork. For the government agencies, asset investors, and businesses who are responsible for such buildings, the prediction of wall tie corrosion losses and hence the structural integrity of masonry walls becomes of interest.

The Newcastle earthquake was a tragic event where subsequent investigations concluded that the severe corrosion of wall ties at and within the mortar bed joint was observed in numerous walls [2]. The ties observed their most severe losses closer to the outer masonry leaf. This external leaf is designed to protect the inner load-bearing leaf from elements such as marine salt spray. Despite this area of the wall tie with most corrosion being sheltered by the external leaf, atmospheric corrosion models are still applied to predict wall tie corrosion, for example, the one created by Hagel et al. [3]. The International Organization for Standardization have also considered that other models consider wall tie material loss in a similar manner. The application of the models (ISO 9223 and 9226), the ISOCORRAG model from ASTM International, and ICP from the UNECE and MICAT databases are also available and were recently reviewed [4,5]. Hagel's model predicts corrosion rates based on electrochemical principles and are calibrated to nine galvanised tie specimens from five separate buildings in four different Canadian cities. The ISO and ISOCORRAG models estimate the corrosion rates of a metal by establishing a corrosivity category and then selecting a corresponding corrosion rate from within the set ranges established for each category. The ISO/ISOCORRAG models are based on the data collected from several unsheltered environments around the world. All three models have only anecdotally been compared to long-term warm temperate coastal empirical data, despite such environments being prone to a potentially accelerated loss of alkalinity. As the models are often used for the long-term prediction of corrosion losses, this research looks to instead correlate the corrosion of wall ties with the alkalinity of the mortar mix whilst in the proximity of breaking surf.

Unfortunately, and somewhat expected, decade-long numerical modelling extrapolations of natural phenomena are of limited benefit without empirical evidence and support. A perhaps more realistic approach would draw from the extensive corrosion of steel reinforcement in concrete (cement, sand, lime, rock, water) literature in an attempt to determine the likely correlations with the corrosion of wall ties within mortar (cement, sand, lime, water). Particularly, high concentrations of calcium, sodium, and potassium hydroxide ions from hydrated Portland cement result in concrete and mortar mixes having high alkalinity [6-8]. As postulated, the corrosion of steel reinforcements, which are dependent on concrete cover thickness, can worsen once the $\mathrm{pH}$ levels drop to a certain limit, typically below 9 [6]. Vast literature exists on factors relating to the loss of alkalinity in concrete. Broomfield [8] covered aspects of carbonation, which is a natural phenomenon that results from the interaction of $\mathrm{CO}_{2}$ in the atmosphere and alkaline hydroxides in the concrete or mortar over time. Bertolini et al. [9] also describe aggressive ion (e.g., chloride) penetration and diffusion within concrete as initiators of corrosion. Despite these well-established theorems, however, recent studies from Melchers and Chaves [6,10] observed a loss of alkalinity in concrete via other means and irrespective of measured chloride levels. This paper explores the postulation that mortar $\mathrm{pH}$ is a key factor that affects the corrosion of different wall tie materials. In particular, it looks at how noticeable changes in the $\mathrm{pH}$ could indirectly infer changes in potentially changing environmental variables. Results from empirical field exposure surveys are used. One site is a few hundred meters from breaking ocean, near Trigg Beach WA, which is classified as having a very high corrosivity category according to ISO 9223 [4]. The following section describes the methodology, which is derived from recent field trials conducted at the comparison site in Belmont New South Wales (NSW) by Jardim do Nascimento and her colleagues [11]. 


\section{Materials and Methods}

Empirical results from two similar coastal test sites were used to comparatively investigate the effect of material choice on corrosion rate-Trigg, WA, and the recently reported studied Belmont, NSW, Australia [5,11]. The Belmont test site is a naturally aggressive salt spray environment that is located on the southeast boundary of the Hunter Water sewage treatment plant and is a recognized corrosion test site [12]. Located $200 \mathrm{~m}$ from the sea, the average annual rainfall is $1142 \mathrm{~mm}$, the average annual relative humidity $(\mathrm{RH})$ is $65 \%$, and the time of wetness (TOW) is $5650 \mathrm{~h} /$ year. The airborne atmospheric chloride ranges from 250 to $350 \mathrm{mg} /\left(\mathrm{m}^{2} /\right.$ day), and the one-year corrosion rate ranges from 100 to $600 \mathrm{~g} /\left(\mathrm{m}^{2} /\right.$ year $)$, with a standard deviation $300 \mathrm{~g} /\left(\mathrm{m}^{2} /\right.$ year $)$ [11]. The air is free of pollutants such as sulphur dioxide, according to the standard [12]. Further long-term environmental site details are readily available in the literature, including through the Australian Bureau of Meteorology [13,14].

In the case of Trigg, Perth, WA, the main test site was chosen due to its high wind speeds. Increased windspeed is thought to influence the salt deposition rate and thus influence the atmospheric corrosion rates. The Trigg site has unshielded views of a segment of a popular Perth surf coast. The test rig where samples were exposed for 14 months was located approximately $270 \mathrm{~m}$ from the average tide level and $20 \mathrm{~m}$ up a $35 \mathrm{~m}$ high hill. The design wind for the Triggs site can be classified by standard AS 4055:2021 [15]. The wind loads for housing is borderline N2/N3 when using the direct standard, and an equivalent wind speed from AS/NZS 1170.2:2021.Structural design actions Part 2: Wind actions [16]: An N3 wind classification results when both approaches are used for the Belmont site, with the Trigg site having a maximum design wind speed of approximately $15 \%$ less than the Belmont site for wind at a $4 \mathrm{~m}$ height (average roof height of a single storey dwelling) or that is $5 \%$ greater than the Belmont site, meaning that the samples were taken at an average height 1.5 at the test rig. A number of factors affect these calculations, including shielding based on ultimate wind versus prevailing winds, the angle of incidence of most winds versus shielding, and the differences in shielding and terrain for the heights and wind directions that are considered to be applicable. The Trigg site is approximately $12 \mathrm{~km}$ from the Bureau of Meteorology Swanbourne weather station, which has an average rainfall of $732 \mathrm{~mm}$ per year, or $897 \mathrm{~mm} /$ year averaged over the exposure period. The Swanbourne station has an average annual RH of $61 \%$ (based on average measurements from 1993 to 2021) [14]. Both the Belmont and Trigg test sites have an R4 durability classification according to AS2699.1:2000-Built-in components for masonry construction; Part 1, Wall ties [17,18]: Based on distance to the shoreline, the Belmont site has a C5 classification, and the Trigg site has a C4 classification as per Table 4.1 of AS 4312:2019-Atmospheric corrosivity zones in Australia [12].

As per Figure 1, the test specimens consisted of standard-sized $\left(230 \times 110 \times 76 \mathrm{~mm}^{3}\right)$ clay-fired masonry brick couplets with $4 x$ identical pairs of non-seismic brick ties embedded in the mortar joint. The material of each wall tie pair was chosen based on AS3700, Masonry Structures [17], and AS2699, Built-in components for masonry construction [18], and the wall tie exposure classification ratings R2 to R4. The chosen materials consisted of (R2) $300 \mathrm{~g} / \mathrm{m}^{2}$ galvanized carbon steel, (R3) $470 \mathrm{~g} / \mathrm{m}^{2}$ galvanized carbon steel, (R3) $304 \mathrm{~L}$ stainless steel, and (R4) 316 L stainless steel. Each was embedded in different mortars.

To investigate the potential passivating effect of alkalinity, each set of $8 x$ ties were embedded in M1, M2, and M3 class mortars [17]. The M1 mortar was a heritage mix of lime and sand (i.e., no cement), M2 consisted of a modern lean cement mix, and M3 was a modern cement mortar that is commonly used in present-day construction [17]. All of the mortars were mixed from the same batch: Portland cement (General Purpose), local washed beach sand, hydrated plasterer lime, and soft tap water. No additives were used. The mix class volumes of the mortar mixes (Cement: Lime: Sand) were M1 = 0:1:3, with water added until a workable condition was reached, $\mathrm{M} 2=1: 2: 9$, with a water/cement ratio of 1.90, and M3 = 1:1:6, with a water/cement ratio of 2.0 as per AS3700 [17]. The mortar $\mathrm{pH}$ was measured after curing and after recovery using PH test strips (Macherey-Nagel pH- 
Fix 0-14PT). The mortar was sampled from various positions within the couplets across the width of the bed joint. A slight variation in the $\mathrm{pH}$ was observed across the width, but careful attention was given wall ties when samples were taken next to the wall ties. These are presented in Table 1 . Approximately $5 \mathrm{~g}$ of mortar powder was carefully collected from all of the mortar samples, which was then crushed with a mortar and pestle, and was then mixed with approx. $25 \mathrm{~mL}$ of distilled water in a sterile glass beaker for $\mathrm{pH}$ measurements.

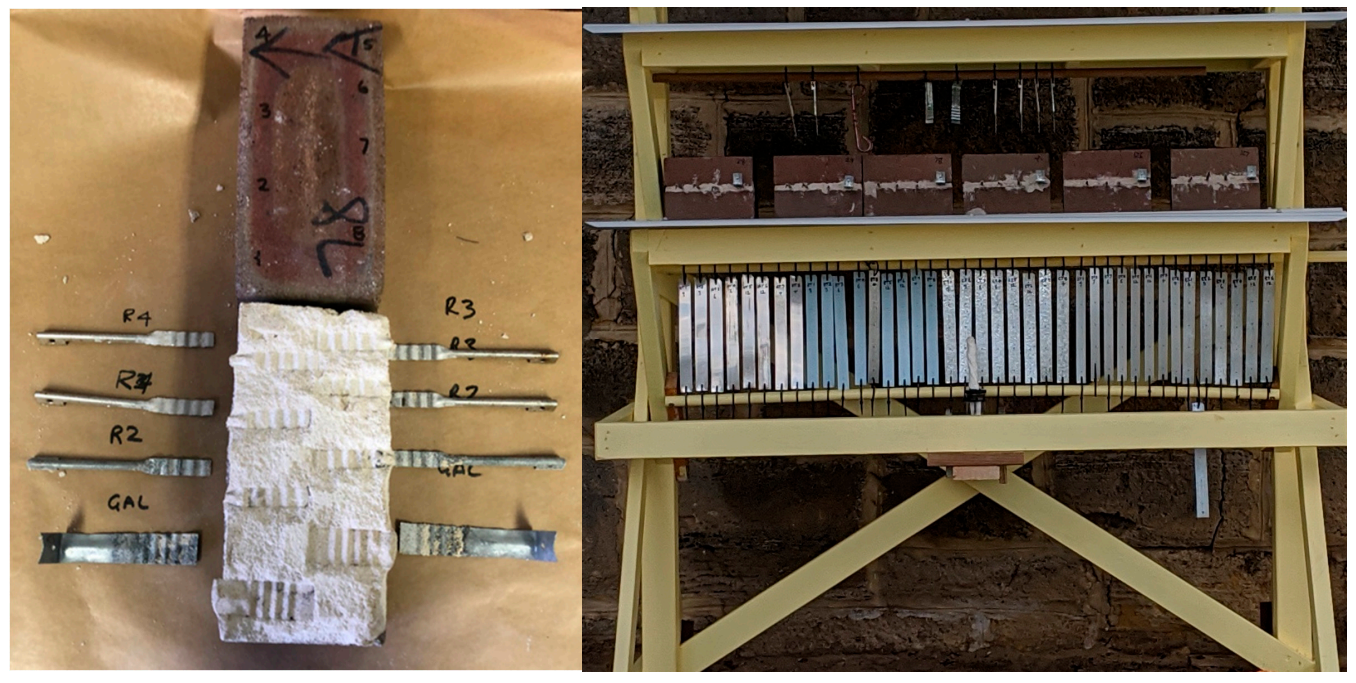

Figure 1. Detail of an example masonry couplet with $8 \times$ brick veneer (left) wire ties [11]. Exposure rack (right); Trigg, Perth, also shown. Three classes of ties are present per coupling. From top to bottom, the material of the duplicate tie samples: (R2) $300 \mathrm{~g} / \mathrm{m}^{2}$ galvanized, (R3) $470 \mathrm{~g} / \mathrm{m}^{2}$ galvanized, (R3) 304 L stainless teel, and (R4) 316 L stainless steel. From left to right, duplicate M1, M2, M3 couplets. The metals samples hanging below the masonry couplets are part of another investigation.

Table 1. Alkalinity $(\mathrm{pH})$ measurements of the various masonry couplet mortar mixes taken prior and after exposure at Trigg, Perth.

\begin{tabular}{|c|c|c|c|}
\hline Mortar Mix Class & Wall Tie Material & pH 15 Days after Curing ${ }^{2}$ & pH at Recovery ${ }^{2}$ \\
\hline \multirow{4}{*}{ M1 $(0: 1: 3)^{1}$} & (R2) $300 \mathrm{~g} / \mathrm{m}^{2}$ galvanized & 12.5 & 7.5 \\
\hline & (R3) $470 \mathrm{~g} / \mathrm{m}^{2}$ galvanized & 12.5 & 7.5 \\
\hline & (R3) 304 L Stainless Steel & 12.5 & 7.5 \\
\hline & (R4) 316 L Stainless Steel & 12.5 & 7.5 \\
\hline \multirow{4}{*}{ M2 (1:2:9) } & (R2) $300 \mathrm{~g} / \mathrm{m}^{2}$ galvanized & 13.0 & 8.0 \\
\hline & (R3) $470 \mathrm{~g} / \mathrm{m}^{2}$ galvanized & 13.0 & 8.0 \\
\hline & (R3) 304 L Stainless Steel & 13.0 & 8.0 \\
\hline & (R4) 316 L Stainless Steel & 13.0 & 8.0 \\
\hline \multirow{4}{*}{ M3 (1:1:6) } & (R2) $300 \mathrm{~g} / \mathrm{m}^{2}$ galvanized & 13.0 & 8.5 \\
\hline & (R3) $470 \mathrm{~g} / \mathrm{m}^{2}$ galvanized & 13.0 & 8.5 \\
\hline & (R3) 304 L Stainless Steel & 13.0 & 8.5 \\
\hline & (R4) 316 L Stainless Steel & 13.0 & 8.5 \\
\hline
\end{tabular}

${ }^{1}$ Mortar mix class volume ratios (cement: lime: sand) as per AS3700 [17]. ${ }^{2}$ Tabled values are averaged from several pH measurements taken from each of the mortars surrounding each of the wall tie materials.

Prior to embedment, all of the wall tie samples were weighed using a laboratory grade balance (Mettler PJ3000 with $0.01 \mathrm{~g}$ sensitivity). All of the masonry couplets were constructed according to standardised embedment criteria and had an embedment anchorage that was no less than half the width of the unit [18] and were cured for 15 days, allowing sufficient unit bond strength to develop. Curing also decreased the chances of microcracking occurring in the bed joint during transport to the exposure site. Care was taken to avoid any contact, and thus any galvanic effect $[5,11]$, between the ties. Before embedment, all of the wall tie specimens had any oil and residues cleaned off with mineral turpentine, 
were rinsed under tap water, and were dried and weighed to the nearest $10 \mathrm{mg}$. This design allowed the wall tie specimens to be simultaneously exposed to atmosphere and embedment corrosion. Moreover, similar to the microclimate within a wall, any humidity accumulation within the mortar bed was captured.

A total of 12 test masonry couplets each containing $4 x$ pairs of identical wall ties (Figure 1 left) as well as separate standalone control wall tie replicates were prepared for the Perth test site. Each test couplet was individually identified with a sequential number from 1 to 12, and each had a side labelled as A (sea-facing) and B. All of the couplets were placed on sheltered timber-elevated exposure racks ( $1.5 \mathrm{~m}$ above ground) in order to facilitate salt spray exposure (Figure 1 right). All of the measurements aligned with previously recorded salt deposition rates [12].

\section{Results}

Figure 2 presents the corrosion loss measured for the duplicate wall ties exposed for fourteen months at Trigg, WA, for each wall tie material that was tested compared to previously reported results $[3,4,19]$. Although not elaborated here, corrosion thickness loss the infers material loss of the cross-section, which is why the mass loss is presented as a percentage of the overall material strength. Table 1 lists the $\mathrm{pH}$ measurements taken before and after exposure at Trigg. Note that the $\mathrm{pH}$ drops slightly with time as the cement content increases.
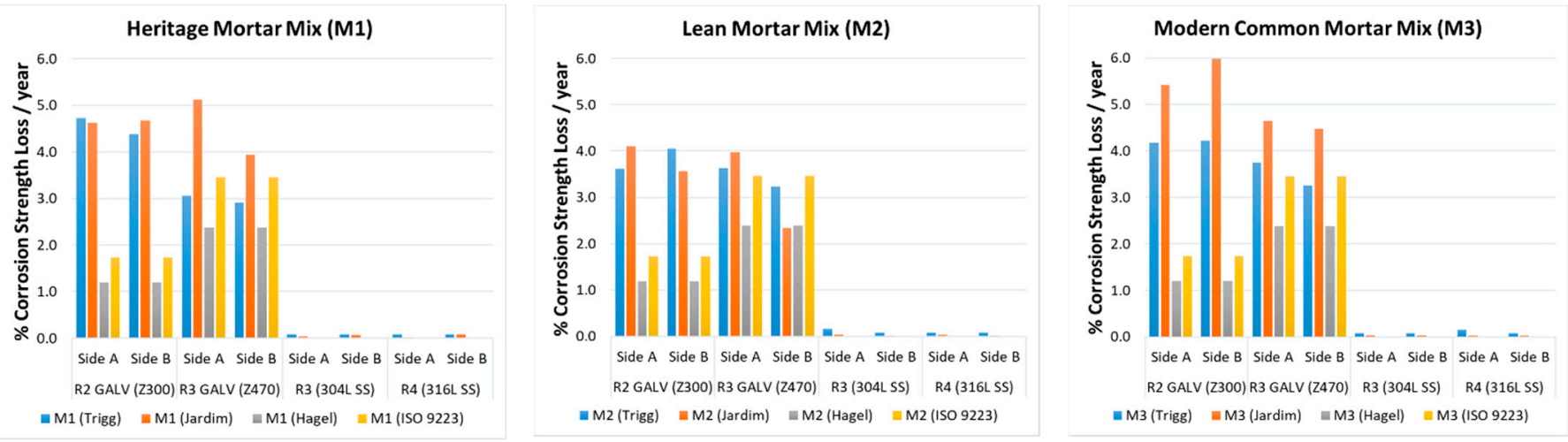

Figure 2. Percentage corrosion strength loss per year that is proportional to the mass loss data for the various wall tie materials that were tested, grouped per in the type of mortar in which they were embedded. Data from this field trial, which are represented via Trigg (blue), are compared to other data sets (Jardim, Hagel and ISO9223). Side A represents samples directly facing the sea, while side B represents the samples facing the opposite direction.

\section{Discussion}

From Figure 2, several observations can be made. The most obvious being that the stainless-steel wall ties, irrespective of their exposure classification rating (i.e., R3 or R4), suffered minimal mass/strength loss. Given the relatively recent revision of the AS3700 and AS2699 standards [17,18], this is not surprising. As somewhat expected, the couplets facing the ocean (i.e., side A) presented higher losses. This could be directly attributed to longer salt spray exposure. This difference in losses is more evident for the R3 $470 \mathrm{~g} / \mathrm{m}^{2}$ samples, but this is not as clear for the R2 galvanised wall tie samples. The variability of the thickness of the galvanised coating may outweigh the variability of the mass losses, explaining these slight discrepancies.

It was expected that the $\mathrm{pH}$ values would remain unchanged, especially when considering the exposure period that was tested. As per Table 1, this was not the case. Considering that the initial $\mathrm{pH}$ was 13 , a noticeable drop was measured upon recovering the samples. Thermodynamically, this would initiate corrosion $[6,7,11]$. Care was taken when handling the couplets in order to avoid any microcracking or loss of the mortar bond; thus, it is likely that the drop in the $\mathrm{pH}$ occurred due to the loss of alkalinity in the mortar. This is 
further evidenced by greater decreases in the $\mathrm{pH}$ of the mixes with lower cement ratios (i.e., M1). It is possible that, for the same exposure period, the M1 mix showed a higher drop in the $\mathrm{pH}$ due to the higher hydroxide buffering capacity of the M2 and M1 mixes, which contain a higher cement concentration. Further detailed studies are required to ascertain this affect in detail; however, a sufficient drop in the $\mathrm{pH}$ to approx. 9 has been shown to expedite the initiation of corrosion in the steel reinforcement bars within concrete and mortar mixes [6,11]. Environmental factors, such as wetness time, chloride deposition, workmanship, fresh mix handling, and curing are all known to have a direct effect on alkalinity loss. Thus, it is difficult to ascertain the exact mechanisms that are in action at this stage. More long-term data, both quantitative and qualitative, are required for a robust predictive tool. For example, SEM, EDX, or a detailed chemical analysis of the mortars could further inform detailed chemical characterisation and modelling initiatives that are conducted in the future.

However, the trends in the short-term data do show that the losses seen here are noticeably higher when compared to other published predictive models. The Trigg results are similar those obtained in Belmont [11]. Considering that the methodology used for the samples at the Trigg site closely followed that used in the recent Belmont field trials [16], this is not surprising. Figure 3 (left) shows a comparative image of an uncorroded R3 $\left(470 \mathrm{~g} / \mathrm{m}^{2}\right.$ galvanised tie) next to ties of the same material following exposure at Belmont and Trigg. Note the darker, more heavily corroded region at the interface between the mortar and atmosphere, which is considered to be the area that is the most susceptible to corrosion losses. The difference in the oxygen concentration at the immediate inside face of the external wall leaf mortar interface, which normally presents high humidity, and the cavity itself, accounts for this. Oxygen concentration and humidity are known to facilitate electrochemical corrosion reactions $[1,6,19]$. Hagel in particular $[3,20]$ considered an electrochemical and thermodynamic function to quantify these losses. This is theoretically relevant; however, the environmental factors and/or microclimates that effect the corrosion losses are both complex and dynamic. This has been argued extensively for a variety of alloys and service environments $[10,13,19]$. ISO 9223, on the other hand is also derived from empirical results [4,12]. For the R2 tie samples, the losses predicted by ISO 9223 are more similar to the Trigg and Belmont field trial results than they are for other wall tie materials. The ISO 9223 prediction still underestimates the amount of corrosion, however. It could be possible that the generalised empirical data used for the ISO 9223, relatively speaking, were obtained for less corrosive conditions than those that are relevant to the Trigg and Belmont test sites. Factors such as the travel of salt-laden air, for example, can be quite variable and site dependent. Future studies should also consider the variations that may be present in the fourteen-month data captured through two winters versus fourteen-month data captured starting from a different season.

To perhaps shed light on how data variability may or may not play a role in long-term (i.e., decades long) circumstances, in situ observations for two coastal masonry buildings are reported [19]. An opportunity arose to inspect the Newcastle City Council Building, a heritage-listed three-story stone-clad building supported by a steel frame built between 1927 and 1929. Close inspection of the corroded extruded round steel tie fixings occurred during remedial works on the external facade. These were generally $300 \mathrm{~mm}$ long with variable diameters, usually $12 \mathrm{~mm}$. An example of the condition of an existing tie is shown in Figure 3 (centre). Despite showing an approx. $4 \mathrm{~mm}$ loss, this was not always the case with other measured fixings. Interestingly, similar observations could be made from in situ cavity inspections of a late 1960's eight-story residential building in Sydney (Figure 3 right). Each level of the building was inspected, and those with less exposure to the sun (i.e., more often wet) presented higher losses. Yet, within the same elevation, not all ties within the same cavity had the same level of corrosion. Some presented approximately $3 \mathrm{~mm}$ losses while others presented only $0.5 \mathrm{~mm}$ losses. Both of the inspected buildings were only a few hundred meters from breaking ocean waters. 

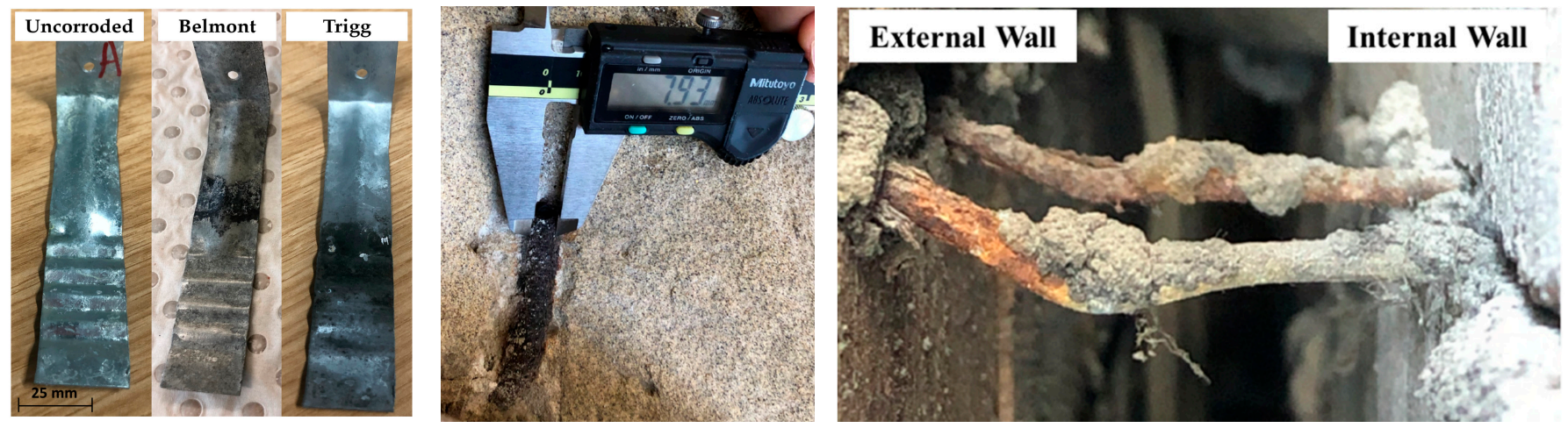

Figure 3. Comparative images of corroded metal wall fitments. Uncorroded control exposed at Belmont, NSW, and exposed at Trigg, WA, (R3) $470 \mathrm{~g} / \mathrm{m}^{2}$ Galvanised veneer wall ties (left); BHP round bar steel fitment used for masonry façade fixings at the Newcastle City Councill Heritage building (center); and comparative external wall metal tie corrosion of a 1960's multi-story cavity masonry residential building in Sydney (right) [19].

From the observations reported here, it is clear that the prediction of long-term corrosion of masonry wall ties is a complex and dynamic phenomenon that needs careful attention. Models have been proposed to pre-empt intervention and or remediation strategies in order to improve building safety and serviceability; however, more empirical data are needed to improve these estimations, particularly in light of the potential electrochemical passivation of the metal fitments over time. In situ electrochemical tests could potentially provide further insight towards the understanding of local corrosion kinetics; however, local corrosion kinetics are difficult to monitor over time. $\mathrm{pH}$ levels have been postulated to directly influence the initiation of corrosion kinetics in mortar-embedded steels; however, losses in alkalinity are currently too challenging to generalise. Image analysis using computer learning variables could theoretically work; however, the correlation between internal corrosion losses would also have to be determined. This could become a challenge when the image correlation techniques may not have sufficient sensitivity to capture changes such as sub-millimetre wall bowing or cracking over time. As such, further longer-term exposure trials coupled with extensive and detailed building inspections are being conducted. These new and improved models based on longer term empirical data will then inform practical tools that will be developed for building assessment, cost-effective monitoring, and rectification, assisting in the management of existing masonry buildings.

\section{Conclusions}

Yearly corrosion strength losses derived from fourteen-month empirical field mass loss data are reported and demonstrate higher corrosion losses than those predicted by published predictive models for galvanized fitments. The results suggest that in certain environments, further investigation may be prudent to ensure the integrity of masonry walls approaching their design life (typically 50 years) and with wall ties experiencing mass losses. This study provides further concern regarding the integrity of aged buildings built prior to modern wall fitment material standards. Of particular concern to Australia are buildings predating 1990, after which the durability of wall ties was upgraded following the Newcastle earthquake. These include the galvanized ties that are commonly used in severe marine environments, contrary to current building standards.

The findings suggest that care must be taken when establishing generalised models to extrapolate long-term strength loss. Empirical long-term models that quantitatively and qualitatively account for natural environmental and microclimate complexities are recommended. As there are numerous variables that are related to corrosion, including humidity, temperature, presence of airborne particulates, and moisture, the influence of mortar $\mathrm{pH}$ was investigated as a common measurable variable. 
The loss in mortar alkalinity ( $\mathrm{pH})$, particularly for higher cement mixes, could expedite the corrosion initiation of the steels within mortars and should be monitored to inform electrochemical and thermodynamic modelling initiatives.

Author Contributions: Conceptualization, I.A.C. and S.d.P.; methodology, B.J.d.N., G.F. and I.A.C.; field work and maintenance, G.F. and B.J.d.N.; formal analysis, I.A.C. and B.J.d.N.; investigation, I.A.C., G.F. and S.d.P.; resources, I.A.C. and S.d.P.; data curation, I.A.C. and B.J.d.N.; writing—original draft preparation, I.A.C.; writing-review and editing, I.A.C. and S.d.P.; visualization, I.A.C. and S.d.P.; project administration, I.A.C. and S.d.P.; All authors have read and agreed to the published version of the manuscript.

Funding: This research received no external funding.

Institutional Review Board Statement: Not applicable.

Informed Consent Statement: Not applicable.

Data Availability Statement: Not applicable.

Acknowledgments: The authors are very grateful for the technical support provided by Lucas Van Woensel in supporting the post-processing of the data. The authors also acknowledge the support from the Belmont Water Treatment Plant and the Trigg residents for ensuring a safe and controlled exposure site for testing. The kind support from the Western Australian Government Department of Mines, Industry and Regulation-Building and Energy and the Geological Survey of Western Australia laboratory is also acknowledged and appreciated.

Conflicts of Interest: The authors declare no conflict of interest.

\section{References}

1. Urban Development Institute of Australia-Western Australia 2020, Modern Methods of Housing Construction, 16 p. Available online: https:/ / www.udiawa.com.au/wp-content/uploads/2021/01/FINAL-UDIA-Report-Modern-Methods-of-Construction.pdf (accessed on 25 August 2021).

2. Page, A.W.; Kleeman, P.W.; Stewart, M.G.; Melchers, R.E. Structural aspects of the Newcastle earthquake. In Proceedings of the Second National Structural Engineering Conference, Institution of Engineers, Adelaide, Australia, 15-17 February 1990.

3. Hagel, M.D.; Lissel, S.L.; Sturgeon, G.R. Comparison of Theoretical and Empirically Determined Service Lives for Wall Ties in Brick Veneer Steel Stud Wall Systems, Special Issue on Masonry. Can. J. Civ. Eng. 2007, 34, 1424-1432. [CrossRef]

4. International Organization for Standardization. ISO 9223 Corrosion of Metals and Alloys. Corrosivity of Atmospheres-Classification, Determination and Estimation, 2nd ed.; International Organization for Standardization: Geneva, Switzerland, 2012.

5. Jardim Do Nascimento, B.; Chaves, I.A.; Masia, M.J.; Melchers, R.E. A field investigation into long-term corrosion of metal wall ties in masonry veneer construction. In Proceedings of the 10th Australasian Masonry Conference, Think Brick Australia, The University of Newcastle, Concrete Masonry Association Of Australia, Sydney, Australia, 10 February 2017.

6. Melchers, R.E.; Chaves, I.A. A study of initiation and active reinforcement corrosion in conventional reinforced concrete. In Proceedings of the Corrosion and Prevention 2016, Australasian Corrosion Association, Auckland, New Zealand, 11-13 November 2016; p. 33.

7. Melchers, R.E.; Chaves, I.A. Service Life Estimation of Concrete Infrastructure, Chapter in Eco-Efficient Repair and Rehabilitation of Reinforced Concrete Structures; Woodhead Publishing: Sawston, UK, 2017; pp. 15-41.

8. Broomfield, J.P. Corrosion of Steel in Concrete: Understanding, Investigation and Repair; CRC Press: Boca Raton, FL, USA, 2007.

9. Bertolini, L.; Carsana, M.; Gastaldi, M.; Lollini, F.; Redaelli, E. Corrosion of steel in concrete and its prevention in aggressive chloride-bearing environments. In Proceedings of the 5th International Conference on Durability of Concrete Structures, Shenzhen, China, 30 June 2016.

10. Melchers, R.E.; Chaves, I.A. Reinforcement corrosion in marine concretes-2: Long-term effects. Am. Concr. Inst. Mater. J. 2020, $117,217-228$.

11. Jardim Do Nascimento, B.; Chaves, I.A.; Masia, M.J.; Melchers, R.E. Corrosion behaviour of mortar embedded wall-ties in natural and artificial environments. In Proceedings of the Corrosion \& Prevention 2019, Australasian Corrosion Association, Melbourne, Australia, 24-27 November 2019.

12. AS 4312 Atmospheric Corrosivity Zones in AUSTRALIA; Standards Australia: Sydney, Australia, 2020 ; ISBN 073378555.

13. Jeffrey, R.; Melchers, R.E. Five year observations of corrosion losses for steels at a severe marine atmospheric site. In Proceedings of the Corrosion and Prevention 2014, Australasian Corrosion Association, Darwin, Australia, 16-19 November 2014.

14. Australian Bureau of Meteorology. Climate Statistics for Australian Locations. 2021. Available online: http://www.bom.gov.au/ climate/averages/tables/cw_009215_All.shtml (accessed on 6 September 2021).

15. AS 4055 Wind Loads for Housing; Standards Australia: Sydney, Australia, 2021; ISBN 9781743423233. 
16. AS/NZS 1170.2 Structural Design Wind Actions; Part 2: Wind Actions; Standards Australia: Sydney, Australia, $2021 ;$ ISBN 9780733798054.

17. AS 3700 Masonry Structures; Standards Australia: Sydney, Australia, 2018; ISBN 9781760359898.

18. AS 2699 Built-in Components for Masonry Construction, Part 1: Wall Ties; Standards Australia: Sydney, Australia, 2018 ; ISBN 073373023.

19. Jardim do Nascimento, B. Predicting Masonry Brick-Veneer and Cavity-Brick Wall-Tie Corrosion. Ph.D. Thesis, The University of Newcastle, Callaghan, Australia, 2021.

20. Ansari, T.Q.; Luo, J.; Shi, S.Q. Modelling the effect of insoluble corrosion products on pitting corrosion kinetics of metals. NPJ Mater. Degradation. 2019, 3, 28. [CrossRef] 